\title{
Chitosan and Liposomes Nanoparticles Encapsulated Cinnamon Extract: Antiproteolytic Activity and Wound Healing Efficiency of Diabetic Rats \\ Running Head: Chitosan vs Liposomes Nanoparticles as Drug Delivery Carriers
}

\author{
Bassma H. Elwakil ${ }^{1}$, Doaa Awad ${ }^{2}$, Ahmed A. Hussein ${ }^{3}$, \\ Reem A. Harfoush ${ }^{4}$, and Yousry M. Gohar ${ }^{5}$ \\ ${ }^{1}$ Medical Laboratory Department, Faculty of Allied Medical Sciences, Pharos \\ University in Alexandria, Alexandria, Egypt. \\ ${ }^{2}$ Biochemistry Department, Faculty of Science, Alexandria University, \\ Alexandria, Egypt. \\ ${ }^{3}$ Biotechnology Department, Institute of Graduate Studies \& Research, \\ Alexandria University, Alexandria, Egypt. \\ ${ }^{4}$ Medical Microbiology and Immunology Department, Faculty of Medicine, \\ Alexandria University, Alexandria, Egypt. \\ ${ }^{5}$ Botany and Microbiology Department, Faculty of Science, Alexandria \\ University, Alexandria, Egypt. \\ *Corresponding author. E-mail:Bassma.hassan@pua.edu.eg \\ https://doi.org/10.12982/CMUJNS.2020.0039
}

Received: February 21, 2020

Revised: May 1, 2020

Accepted: May 8, 2020

\begin{abstract}
Diabetic foot infection is a major concern between diabetic communities as it is increasing rapidly with more virulent organisms. These virulent organisms include the flesh and bone eating bacteria which produce proteolytic enzymes in order to hydrolyze the skin, flesh and bone. When the infection spreads, physicians lean to amputation followed by a long term of broad spectrum antibiotics. Even after complete eradication of bacteria, their proteolytic enzymes remain in the blood circulation which leads to prior amputation. Thirty three bacterial isolates were isolated from foot ulcers of diabetic patients. The most prevalent isolates were Proteus mirabilis and Pseudomonas aeruginosa. The selected bacterial isolates were tested for protease production on different protein sources including collagen (the most abundant compound in human's connective tissue). Eighteen herbal extracts were examined for their effect against the proteolytic activity of the selected
\end{abstract}


isolates. Cinnamon ethanolic extract was the most effective anti-proteolytic agent. Chitosan and liposomes nanoparticles loaded with cinnamon ethanolic extract were prepared and their physicochemical characteristics were evaluated. For assessment of wound healing efficiency, gel of both Chitosan and liposomes nanoparticles loaded with cinnamon ethanolic extract was tested in wounded diabetic rats and it was found that liposomes/cinnamon gel was more effective as wound healing remedy.

Keywords: Diabetic foot, Proteases, Amputation, Cinnamon, Chitosan nanoparticles, Liposomes

\section{INTRODUCTION}

Complications of a wound associated with bacterial infection delays healing and in some cases it can be fatal. In diabetic foot patient, infected wound is a major concern because it can lead to hospitalization and amputation as the bacteria get more virulent by time. Foot ulcers infection is commonly severe complication in diabetes. The clinical diagnosis of infected ulcer are based on local signs and symptoms include purulent secretion, redness, warmth, swelling, pain, offensive odor and delayed healing (Lepäntalo et al., 2011).

Diabetic foot infections (DFI) are mainly polymicrobial, the variability of bacterial virulence factors and the level of host resistance must also be taken into account (Al Wahbi, 2018). One of the bacterial virulence factors is the extracellular proteolytic enzymes which have a key role in host colonization by assisting the pathogen spread into host tissues. They also improve the pathogen survival and growth by increasing (a) the availability of amino acids and (b) toxins diffusion (Dunyach-Remy et al., 2016). In diabetic and arterial foot lesions, Gram-positive aerobic cocci grow in 59\% of cultures (24\% are colonized by $S$. aureus) while Gram-negative aerobes grow in 35\% of cultures (frequently Escherichia coli and Proteus mirabilis) (John and Sharkey, 2018).

The Phytochemical compounds presented in plants' secondary metabolites are gaining enormous attention in the human health care researches especially as new potent antimicrobial agents. However, protease inhibitors (PIs) are still not fully explored which protect the plant itself against diseases, insects, pests, and herbivores (Srikanth and Chen, 2016). Cinnamon has been used as spice for a long time. Cinnamon can be found as True or Ceylon cinnamon (Cinnamomum verum and $C$. zeylanicum) and cassia cinnamon $(C$. aromaticum and $C$. burmannii). Cinnamon has been used as a dietary supplement, antioxidant, antiinflammation, and presently discovered antihyperlipidemia and antiobesity effect properties (Tuzcu et al., 2017). However the anti-proteolytic activity of cinnamon extract wasn't yet fully explored which will be covered in the present manuscript. 
Nanotechnology today is extensively exploring various methods and techniques to concur the infectious diseases (Mishra, 2016). Chitosan is a linear polysaccharide composed of randomly distributed $\beta$-(1-4)-linked D-glucosamine and N-acetyl-d-glucosamine; with varying degree of deacetylation (DD; 40-99 $\%$ ) and MW (Philibert et al., 2017). Commercially, chitosan is mainly obtained from crustacean shells. Due to its safety profile as well as biodegradability, chitosan is gaining more attention. On the other hand, liposomes have been the first to be investigated as drug carriers. They are nano/micro-particular or colloidal carriers, usually with $80-300 \mathrm{~nm}$ size range (Rathor et al., 2017). They are spherical vesicles composed of phospholipids and steroids (e.g., cholesterol), bilayers, or other surfactants and form spontaneously when certain lipids are dispersed in aqueous media where liposomes can be prepared, e.g., by sonication (Matougui et al., 2016). The advantages of encapsulating the natural products in nanocarriers are to protect the natural products from being degraded, and provide a gradual release of the bioactive compounds. In the present study, a comparison between chitosan and liposomes nanoparticles as effective drug carrying systems was evaluated against wounded diabetic rats. This research will be a combination of Cinnamon extract with nanochitosan and liposomes individually to compare the natural extract delivery to the target site with prolonged anti-proteolytic activity.

\section{MATERIALS AND METHODS}

Bacteriological media namely; Blood base agar, MacConkey agar, Mueller Hinton agar, Nutrient agar, and Nutrient broth were purchased from Difco, England. Low molecular weight chitosan powder (100-150 kDA, degree of deacetylation 75-85\%) and Collagen from rat tail (C8897) were purchased from Sigma-Aldrich (St Louis, MO, USA). All other chemicals were analytical grades of known chemical suppliers.

\section{Sample collection}

Foot ulcers of diabetic patients were screened for the presence of proteolytic bacteria and the samples were collected by swabbing and tissue biopsy (Nelson et al., 2016). Samples were provided by the routine lab of the main University hospital, Alexandria, Egypt.

\section{Isolation and identification of the bacterial isolates}

Streak plate method on blood and MacConkey agar plates was used for bacterial isolation. Inoculated plates were incubated at $37^{\circ} \mathrm{C}$ for $(24-48) \mathrm{hrs}$. Different colonies were purified and identified phenotypically and biochemically according to Bergey's manual. 


\section{Herbal extraction}

15 grams of herbals' grinded powders were extracted using $99 \%$ ethanol and then left for 24 hours in dark jars (Abdul Qadir et al., 2017). Each ethanolic extract was evaporated to dryness using rotary evaporator (GRFE2, Goel Scientific, India). Each herbal sample was kindly identified in the Botany department, Faculty of Science, Alexandria Egypt. The herbals that were tested in this research:

- Arugula (Eruca sativa)

- Basil (Ocimum basilicum)

- Black eyed pea (Vigna unguiculata)

- Cinnamon (Cinnamomum verum)

- Clove (Syzygium aromaticum)

- Colocynth (Citrullus colocynthis)

- Coriander (Coriandrum sativum)

- Dill (Anethum graveolens)

- Goldenseal (Hydrastis canadensis)

- Green pepper (Capsicum annuum)

- Green tea (Camellia sinensis)

- Lettuce (Lactuca sativa)

- Magnolia (Magnolia grandiflora)

- Medical onion (Allium cepa)

- Mint (Mentha)

- Saint Jones Wort (SJW) (Hypericum perforatum)

- Soybean (Glycine max)

- Wheat bran (Triticum aestivum)

\section{Screening of bacterial proteolytic activity}

Screening of proteolytic activity was evaluated through spot inoculation of one day old bacterial suspension $\left(10^{5} \mathrm{CFU} / \mathrm{ml}\right)$ on casein and collagen agar plates, the inoculated plates were then incubated at $37^{\circ} \mathrm{C}$ for 24 hours then the diameter of hydrolysis zone was measured using Coomassie brilliant blue (CBB) as visualization method of proteolytic activity (Ortiz et al., 2016).

\section{Confirmatory detection of the flesh and bone eating bacteria}

Complete shaved mice's legs were sterilized using 70\% ethanol for 3 hours then each leg was immersed in $3 \mathrm{ml}$ of one day old bacterial suspension $\left(10^{5}\right.$ $\mathrm{CFU} / \mathrm{ml}$ ) and incubated for 10 days at $37^{\circ} \mathrm{C}$. Visual observation of the flesh and bone hydrolysis was recorded during the incubation period.

\section{Enzyme activity}

The enzyme activity was evaluated using the bacterial cell free extract at $415 \mathrm{~nm}$ at different time intervals (0-3-12-20-24 hours) estimation of protease activity was done by using azo-casein as a substrate and detected by Follin Lowry method (Ortiz et al., 2016). 


\section{Screening of the anti-proteolytic activity of the prepared natural extracts}

On casein agar plates, $500 \mu \mathrm{l}$ of ethanolic natural extract was inoculated one at a time into each plate before solidification. After solidification; the plates were inoculated with $20 \mu \mathrm{l}$ of cell-free extract of the proteolytic bacteria, then the plates were incubated for 24 hours at $37^{\circ} \mathrm{C}$ (Coomassie brilliant blue (CBB) was used for the detection of hydrolysis zone, if no hydrolysis zone was detected then the natural extract under test was considered as active anti-proteolytic agent).

\section{Anti-proteolytic activity of the chosen natural inhibitor}

The same done as with the enzyme activity, but it differs in the addition of $0.5 \mathrm{ml}$ of the natural inhibitor to the mixture of the cell-free extract plus the azocasein and then the absorbance was recorded $(415 \mathrm{~nm})$ at different time intervals ranging from 0 to $24 \mathrm{hrs}$.

\section{GC-MS analysis of cinnamon extract}

GC-MS was used to detect the active compounds with a column CP8944 $30 \mathrm{~m} \times 0.25 \mathrm{~mm} \times 0.39 \mathrm{~mm}$ for separation. The oven temperature was raised from $40{ }^{\circ} \mathrm{C}$ to $230{ }^{\circ} \mathrm{C}$ at constant heating rate of $5{ }^{\circ} \mathrm{C} \mathrm{min}^{-1}$. The active compound in cinnamon extract was identified using the attached software (Kasim et al., 2014). GC-MS analysis was done at National Institute of Oceanography and Fisheries, Alexandria University, Egypt

\section{Nanoparticles preparation}

Preparation of chitosan/cinnamon. According to Rampino et al. (2013), an aqueous acidic solution of chitosan plus cinnamon ethanolic extract was added dropwise under constant stirring to sodium tripolyphosphate (TPP) (1\%) solution which acts as chitosan's crosslinker. Stirring maintained for approximately 10 minutes to allow particle stabilization and the obtained suspension was centrifuged to separate the nanoparticles from unreacted chitosan and TPP. The resultant pellet of nanoparticles was then resuspended in water.

Preparation of liposome/cinnamon. Liposomes were prepared by hydration of a thin lipid film according to Bangham et al. (1974) with the addition of $100 \mathrm{mg}$ cinnamon ethanolic extract. Liposomes were then reserved in $1.5 \mathrm{ml}$ vial, capped and stored in the refrigerator $\left(5^{\circ} \mathrm{C}\right)$.

Nanoparticles characterization. The particle size (PS), polydispersity index (PDI) and Zeta potential of Chitosan and liposomes nanoparticles loaded with cinnamon extract was determined by dynamic light scattering (DLS) technique using Malvern Zetasizer according to El-Refaie et al. (2015). Entrapment efficiency and loading capacity of Chitosan and liposomes nanoparticles loaded with cinnamon extract was assessed according to Elnaggar et al. 2016 and Matshetshe et al. 2018 respectively. Each formulated nanoparticles was diluted with phosphate buffer solution (PBS) $(1: 10 \mathrm{v} / \mathrm{v})$ and centrifuged $\left(15,000 \mathrm{rpm}\right.$ for $\left.15 \mathrm{~min} / 4^{\circ} \mathrm{C}\right)$. Supernatants were measured by 
UV/Vis (Spekol 1300, Analytik Jena, Germany) at $286 \mathrm{~nm}$ with methanol as a blank to measure the unentrapped extract. The entrapment efficiency percentage (EE\%) was calculated according to the following equation:

$$
\mathrm{EE} \%=\frac{\text { Total unentrapped drug }}{\text { Total drug }} \times 100
$$

Preparation of the treating gels. Phase A: Hot Distilled Water 62.5\%, Xanthan Gum 0.5\%, Phase B: Glycerin 2\% and Phase C: Jojoba Oil 9\%, Collagen Protector 3\%, Distilled Water 20\%, Hyaluronic Acid (humectant) $0.5 \%$ and the prepared nanoparticles $2.5 \%$ (liposomes or the prepared chitosan nanoparticles loaded with cinnamon extract one at a time). At first the xanthan gum was sprinkled and stirred with high speed in hot distilled water. Then phase B was added to phase $\mathrm{A}$ with continuous stirring. In order to prepare phase $\mathrm{C}$, hyaluronic acid was sprinkled in distilled water and stirred well to homogenize the solution. Phase A/B was heated up to $66^{\circ} \mathrm{C}$ then phase $\mathrm{C}$ was added under stirring and the remaining ingredients of phase $\mathrm{C}$ was added thoroughly.

Chitosan vs liposomes nanoparticles as drug delivery systems in vivo. The present experiment was performed in an approved animal care center in accordance with the Animal Care and Use Committee (ACUC) at the Faculty of Science, Alexandria University and was in accordance with the International Principles for Laboratory and Care of the European Community Directive of 1986; AU/04/19/01/26/3/02. Forty five albino rats (Rattus norvegicus albinus), 6 months old, weighing 250-325 gram with glucose level $95-112 \mathrm{mg} / \mathrm{dl}$ were randomly assigned to the present experiment. Diabetes was induced by intraperitoneal injection of Alloxan monohydrate to overnight fasted animals at a dose of $100 \mathrm{mg} / \mathrm{kg}$ body weight. Diabetes was confirmed by recording blood glucose values (Okpe et al., 2019). Each rat has blood sugar level more than 200 $\mathrm{mg} / \mathrm{dl}$ were selected for further study. The rats were assigned to one major diabetic group; sub-grouped to nine subgroups ( $\mathrm{n}=5$, each sub-group):

- Control group, in which rats were not infected with bacteria.

- Group I, in which rats were infected with Proteus mirabilis with no treatment regimen.

- Group II, in which rats were infected with Pseudomonas aeruginosa with no treatment regimen.

- Group III, in which rats were infected with Proteus mirabilis and treated with imipenem alone ( $0.1 \mathrm{ml}$ of $150 \mathrm{mg}$ was injected intramuscularly) (imipenem was chosen as a treatment because it has been known as a standard treatment for MDR bacterial infection).

- Group IV, in which rats were inoculated with Proteus mirabilis and treated with chitosan/cinnamon gel once daily. 
- Group V, in which rats were inoculated with Proteus mirabilis and treated with liposomes/cinnamon gel once daily.

- Group VI, in which rats were infected with Pseudomonas aeruginosa and treated with imipenem alone $(0.1 \mathrm{ml}$ of $150 \mathrm{mg}$ was injected intramuscularly).

- Group VII, in which rats were inoculated with Pseudomonas aeruginosa and treated with chitosan/cinnamon gel once daily.

- Group VIII, in which rats were inoculated with Pseudomonas aeruginosa and treated with liposomes/cinnamon gel once daily.

Anesthesia was done by injecting rats intraperitoneal with Somnopentyl (25-30 mg/kg body weight). The trunk hair was shaved, and the skin was then treated with depilatory cream to completely remove hair, washed with water and detergent, and then cleaned with an alcohol wipe. Full-thickness round wounds (2-cm diameter) were made using sterile scissors (Figure 1). The wounds were covered with two transparent film dressings. Then the trunk of the rat was rolled loosely in nonwoven fabric gauze, covering these transparent film dressings, and taped the gauze in place. After 24 hours, the induced wounds were inoculated with $0.2 \mathrm{~mL}$ bacterial suspension (approximately $4.12 \times 10^{9} \mathrm{CFU} / \mathrm{mL}$ ) to generate wound infection model. The wound area was then covered with polyurethane film. The film dressings were changed every 24 hours to add the treating gel (Group IV, V, VII and VIII), until day 7. The wound was measured with a metric ruler. At day 7 after wound formation, all rats were euthanized by pentobarbital sodium overdose (intraperitoneal injection) (Asada et al., 2012).

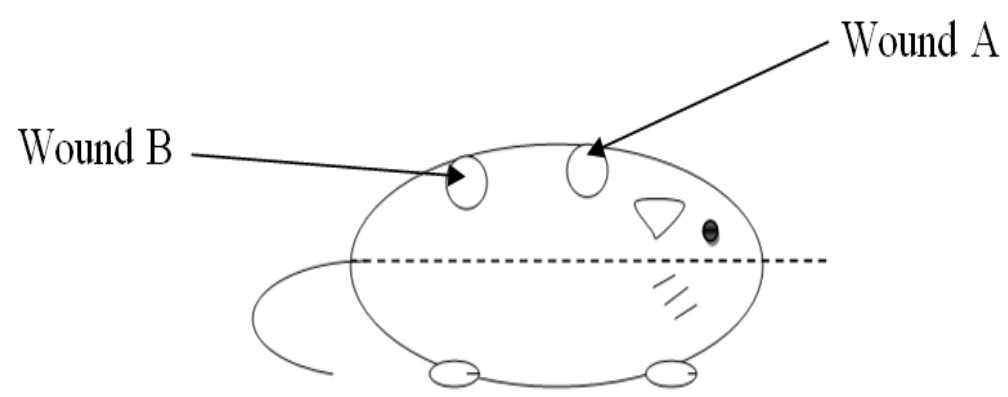

Figure 1. Wound sites A: was closest to the head; was closest to the tail.

\section{RESULTS}

\section{Isolation and identification of the bacterial isolates}

Out of 33 bacterial species isolated from foot ulcers of diabetic patients; $73 \%$ were Gram-negative bacteria and $27 \%$ were Gram-positive. P. mirabilis was the most distributed bacterium (18\%) among the isolated bacteria followed by $P$. aeruginosa (12\%). 


\section{Detection of proteolytic bacteria}

To test the proteolytic activity of the bacterial isolates under test, casein was used as a protein source. Figure 2a illustrated that $P$. mirabilis 3 showed significant proteolytic activity with a hydrolysis zone diameter of $35 \mathrm{~mm}$. While A. baumannii, E. coli, K. pneumoniae, $P$. aeruginosa 3 and $P$. mirabilis 5 were non-proteolytic bacteria. On the other hand, by using collagen as a protein substrate only a few bacterial isolates had the ability to hydrolyze the collagen with $P$. aeruginosa 5 on top $(21 \mathrm{~mm})$ (Figure $2 \mathrm{~b}$ ). The maximum hydrolytic activity of all the protein substrates used was shown by $P$. aeruginosa 5 followed by $P$. mirabilis 3 ; so these two organisms were chosen for further studies.

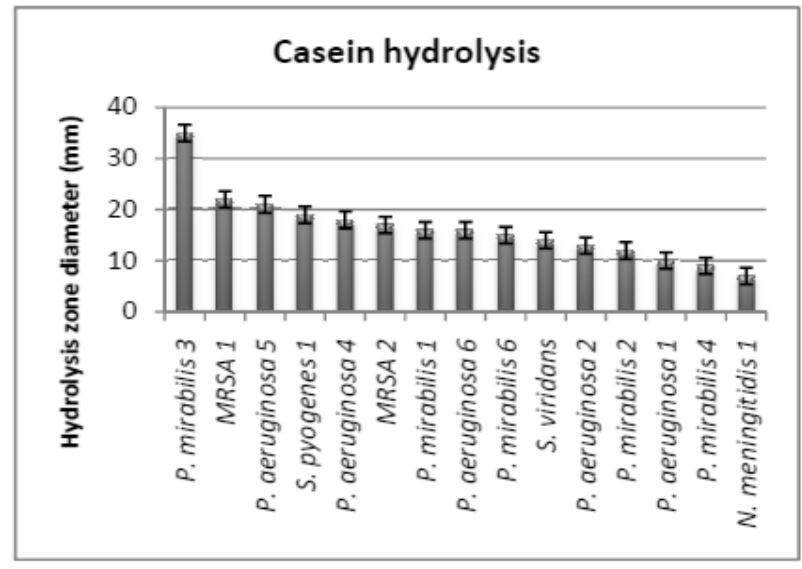

(a)

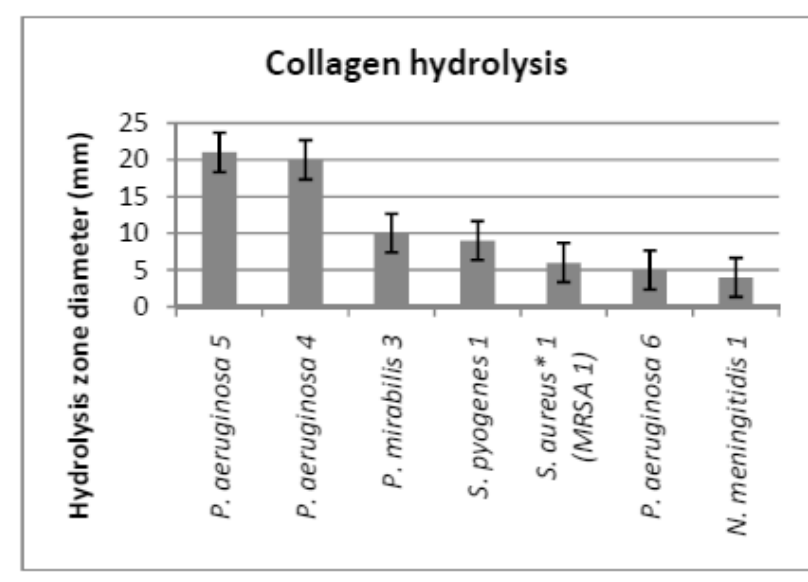

(b)

Figure 2. Casein (a) and Collagen hydrolysis (b).

\section{Confirmatory detection of the flesh and bone eating bacteria}

It was confirmed that the chosen $P$. mirabilis 3 and $P$. aeruginosa 5 (Figure 3 ) were flesh and bone eating bacteria when they showed the ability to completely hydrolyze the skin and the flesh plus hydrolyzing the bones of the mice's sterilized shaved legs.

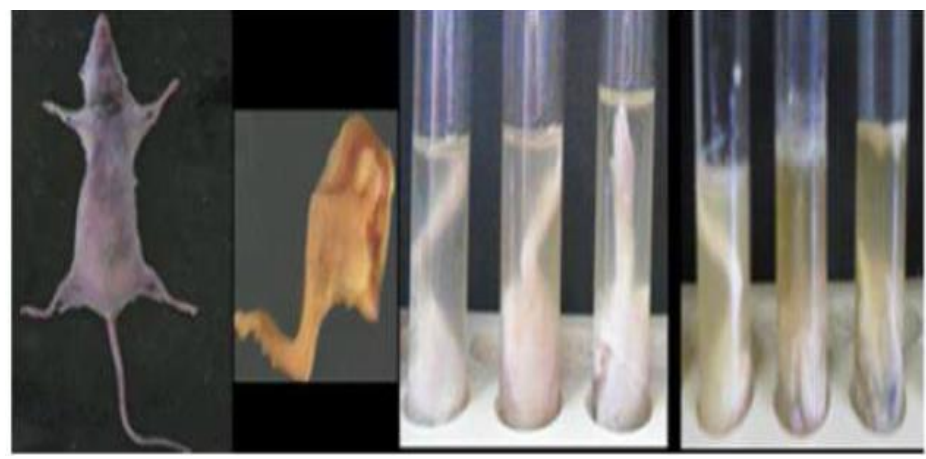

Figure 3. Confirmatory detection of the flesh and bone eating bacteria (control tube on the left, $P$. mirabilis 3 suspension in the middle tube and $P$. aeruginosa 5 suspension on the right). 


\section{Enzyme activity}

The enzyme activity was measured by using Follin Lowry method at different time intervals (Figure 4). The highest protein content was recorded by $P$. aeruginosa 5 at 12 hours $(6.26 \mathrm{mg} / \mathrm{ml})$. This experiment showed that an increasing in protein content till 12 hours or till 18 hours then a significant decrease in protein content was observed. This decrease means activation of proteolytic enzymes (hydrolysis of protein occurred). The highest amount of hydrolysed protein means highest proteolytic activity and that's was recorded in case of Ps. aeruginosa $5(3 \mathrm{mg} / \mathrm{ml})$ (Table 1).

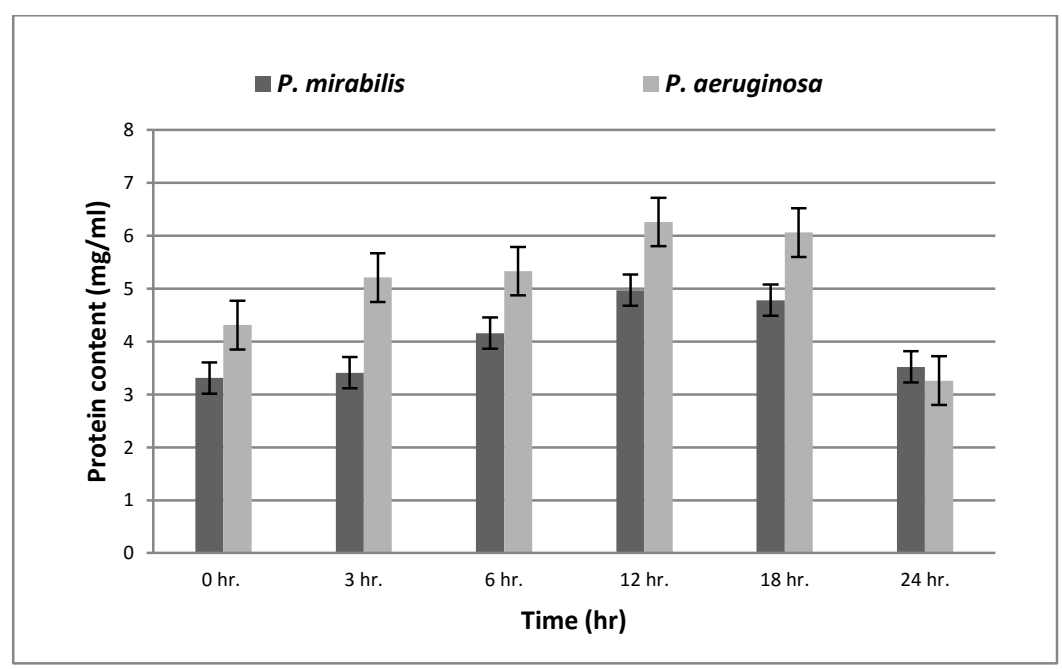

Figure 4. Enzyme activity.

Table 1. Amount of hydrolysed protein.

\begin{tabular}{|l|c|}
\hline Test organism & Hydrolysed protein $(\mathbf{m g} / \mathbf{m l})$ \\
\hline P. mirabilis 3 & 1.45 \\
\hline Ps. aeruginosa 5 & 3.00 \\
\hline
\end{tabular}

\section{The anti-proteolytic activity of different natural extracts}

The antiproteolytic activity of the 18 ethanolic extracts was evaluated against the cell-free extracts of $P$. mirabilis 3 and $P$. aeruginosa 5 . Only 4 herbal extracts showed anti-proteolytic activity (Cinnamon, Colocynth, Goldenseal and SJW respectively). Cinnamon extract had the highest anti-proteolytic activity hence it was chosen for further study (Figure 5). 


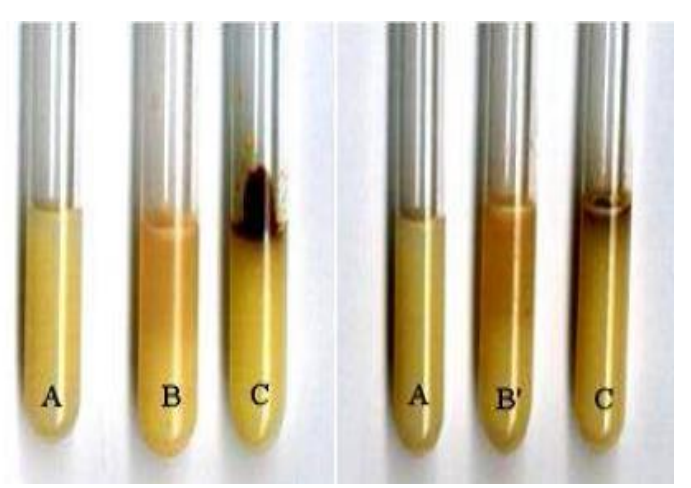

Figure 5. Cinnamon as anti-proteolytic agent where $\mathrm{A}=$ control tube, $\mathrm{B}^{\prime}=P$. mirabilis $3, \mathrm{~B} "=P$. aeruginosa 5 and $\mathrm{C}=$ cell free extract of bacterial isolates under test plus cinnamon extract.

\section{Anti-proteolytic activity of cinnamon extract}

The results were taken at different time intervals ranging from zero time to 24 hours incubation at $37^{\circ} \mathrm{C}$. The cinnamon ethanolic extract showed outstanding results (significantly different $(P<0.05)$ ) with the chosen bacterial samples as it can regularly continue to inhibit the proteolytic activity through 24 hours (Figure $6)$.

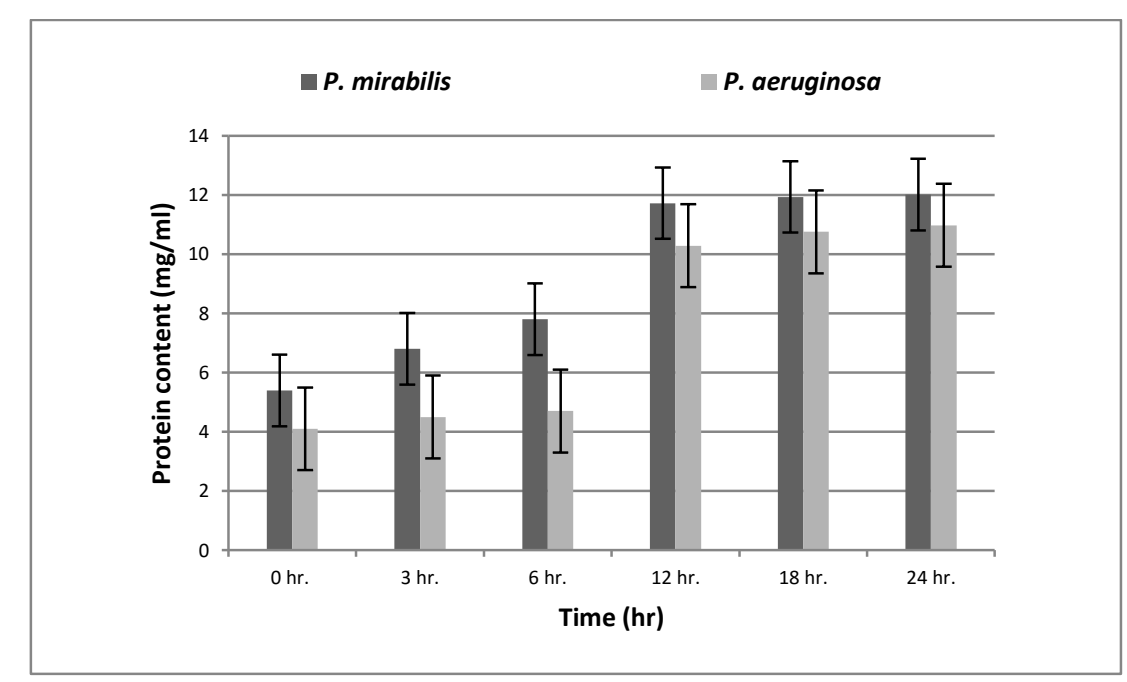

Figure 6. Cinnamon as anti-proteolytic agent.

\section{GC-MS analysis of cinnamon extract}

The major constituent of the cinnamon extract was found to be the cinnamldehyde (45\%) with the highest percentage which supposed to be responsible for the antimicrobial activity (Figure 7), followed by n-Hexadecenoic acid $(27 \%)$ and Trans-13-Octadecenoic acid (18\%). 


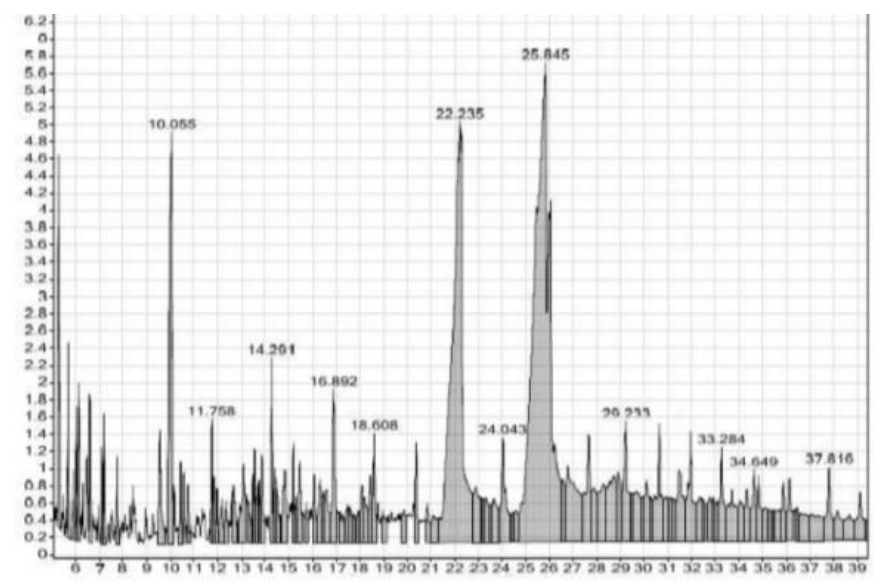

Figure 7. GC analysis of cinnamon extract.

\section{Nanoparticles characterization}

Liposome/cinnamon average size obtained was between 104 and $140 \mathrm{~nm}$ as estimated by transmission electron microscope (TEM) while chitosan/cinnamon nanoparticles average size was between 135 and $252 \mathrm{~nm}$ (Figure 8). DLS study of both nanosystems showed that liposome/cinnamon proved to be more stable with better entrapment efficiency compared to chitosan/cinnamon nanoparticles (PDI 0.2 and 0.3 ; EE\% 84 and 79, respectively) (Table 2).

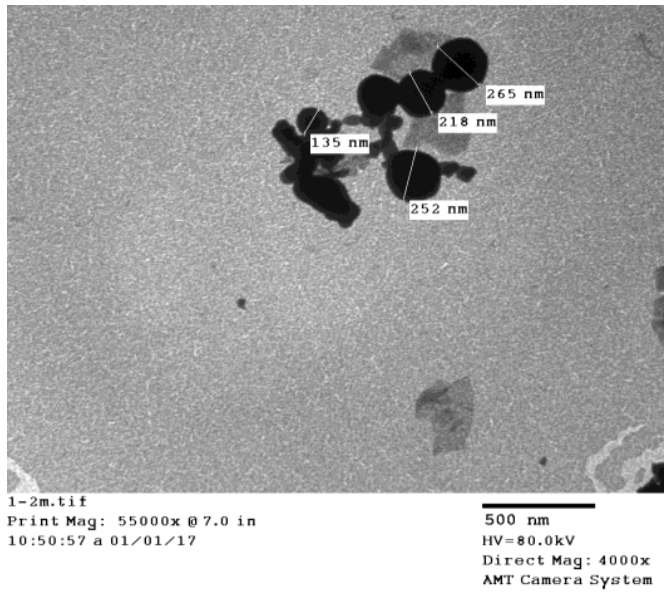

(a)

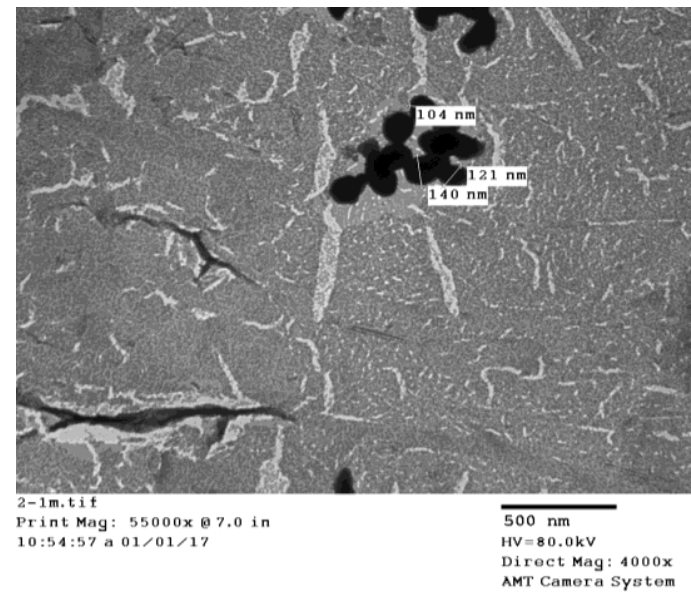

(b)

Figure 8. Transmission electron microscopy analysis for chitosan/cinnamon (a) and liposome/cinnamon (b) nanoparticles. 
Table 2. Chitosan and liposomes nanoparticles loaded cinnamon extract nanoparticles' characterization.

\begin{tabular}{|l|c|c|c|c|c|}
\hline Prepared nanoparticles & Zeta size (nm) & Zeta potential (mV) & PDI & EE\% & LC\% \\
\hline Liposomes/cinnamon & 115 & -40.7 & 0.2 & 84 & 42 \\
\hline Chitosan/cinnamon & 178 & +27.8 & 0.3 & 79 & 39.5 \\
\hline
\end{tabular}

\section{Chitosan vs liposomes nanoparticles as drug delivery systems in vivo}

It was found that different wound sites produced different results. For example, wounds located nearer the head showed accelerated healing but wounds located nearer to the tail showed delayed healing. It was also noticed that liposomes/cinnamon gel was highly efficient and significantly different $(P<0.05)$ as a treatment for infected wounds in comparison to chitosan/cinnamon nanoparticles gel and imipenem respectively (Table 3 and Figure 9 and 10).

Table 3. Wound contraction of dorsal fore and behind wounds.

\begin{tabular}{|c|c|c|c|c|c|c|c|c|c|c|c|c|c|c|}
\hline \multirow{3}{*}{ Groups } & \multicolumn{14}{|c|}{ Wound diameter $(\mathrm{mm})$} \\
\hline & \multicolumn{2}{|c|}{0 time } & \multicolumn{2}{|c|}{2 days } & \multicolumn{2}{|c|}{3 days } & \multicolumn{2}{|c|}{4 days } & \multicolumn{2}{|c|}{5 days } & \multicolumn{2}{|c|}{6 days } & \multicolumn{2}{|c|}{7 days } \\
\hline & WA & WB & WA & WB & WA & WB & WA & WB & WA & WB & WA & WB & WA & WB \\
\hline Ctrl & 15 & 15 & 17 & 20 & 15 & 20 & 15 & 15 & 15 & 13 & 17 & 12 & 15 & 10 \\
\hline P. mirabilis & 15 & 15 & 16 & 18 & 15 & 15 & 12 & 14 & 11 & 12 & 11 & 11 & 10 & 11 \\
\hline P. aeruginosa & 15 & 15 & 17 & 18 & 17 & 17 & 16 & 17 & 15 & 15 & 13 & 15 & 12 & 14 \\
\hline P. mirabilis IMP & 15 & 15 & 18 & 18 & 12 & 13 & 9 & 10 & 8 & 10 & 7 & 10 & 7 & 10 \\
\hline P. mirabilis Cs/cinnamon & 15 & 15 & 17 & 17 & 15 & 15 & 10 & 14 & 9 & 11 & 9 & 10 & 9 & 10 \\
\hline P. mirabilis Lp/cinnamon & 15 & 15 & 17 & 16 & 14 & 12 & 10 & 10 & 7 & 8 & 3 & 5 & 3 & 5 \\
\hline P. aeruginosa IMP & 15 & 15 & 16 & 17 & 14 & 15 & 11 & 11 & 9 & 10 & 7 & 10 & 5 & 9 \\
\hline P. aeruginosa $\mathrm{Cs} /$ cinnamon & 15 & 15 & 18 & 19 & 14 & 14 & 8 & 10 & 6 & 7 & 5 & 6 & 5 & 6 \\
\hline P. aeruginosa Lp/cinnamon & 15 & 15 & 16 & 17 & 12 & 13 & 12 & 11 & 6 & 10 & 5 & 9 & 5 & 8 \\
\hline
\end{tabular}

Note: IMP=Imipenem, Cs=Chitosan and Lp=Liposomes; WA = Dorsal Fore wound, WB =Dorsal Behind wound. 


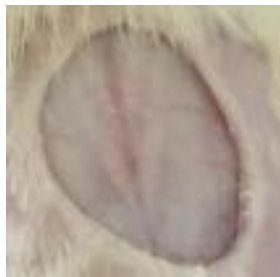

(a)

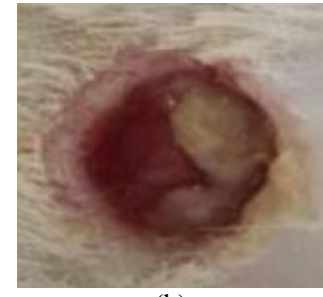

(b)

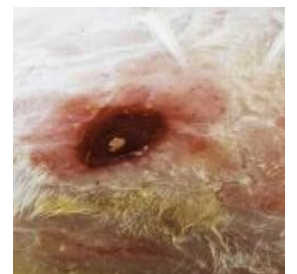

(c)

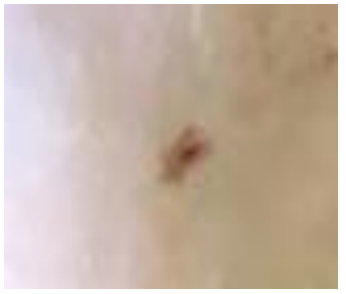

(d)

Figure 9. Wound A morphological appearance (a: Day 0, b: infected nontreated group (day 7), c: chitosan/cinnamon nanoparticels treated group (day 7) and d: Liposomes/cinnamon nanoparticles treated group (day 7)).

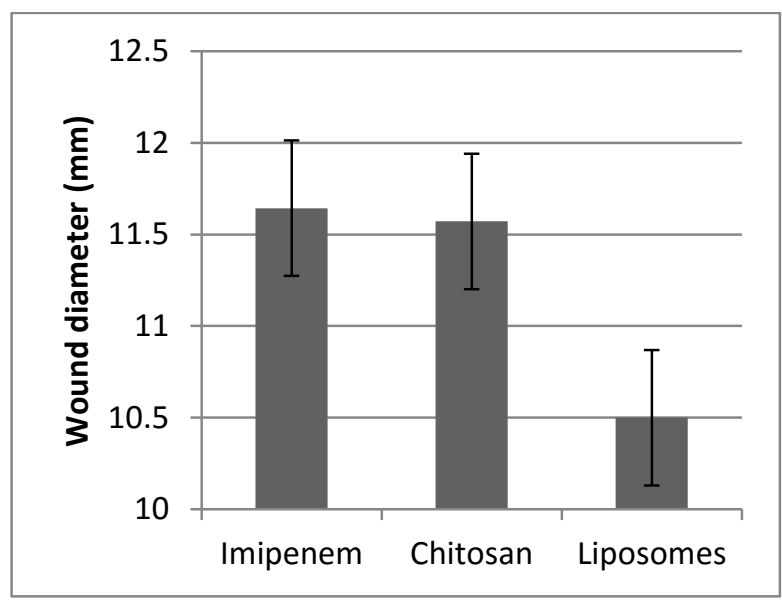

Figure 10. Wound healing efficiency of different treatment regimen.

\section{DISCUSSION}

The virulence inhibition is an established antimicrobial strategy which has been named as 'second-generation' antibiotics. This strategy is basically concerned about inhibiting the bacterial virulence without actually killing the bacteria; hence no resistant strains will be emerged. Bacterial toxins are the most important virulence factor; these toxins were grouped according to the active site in the host cell: '(a) toxins acting outside cells by binding to specific proteins or receptors or by degrading tissue and/or cellular components; (b) toxins altering the permeability of the cell membrane; (c) toxins acting inside cells' (Menestrina et al., 1994).

Hydrolytic activity has been adopted by many pathogenic microorganisms in order to accomplish specific functions during the infective process. Proteases may be secreted by facultative pathogens which have important effect in both infection and saprophytic growth (Jashni et al., 2015). The key point of this research was to find a protease inhibitor whether this inhibition is competitive inhibition (the inhibitor binds to the active site) or non-competitive inhibition (the 
inhibitor binds to an allosteric site) (Shapiro and Vallee, 1991). Natural products were the area of scope to effectively inhibit the bacterial proteases in addition to that the natural products were known as rich source of anti-infective agents (Cushnie and Lamb, 2005). Cinnalmaldehyde is the major component in cinnamon which is credited with its biological activity, safety and can be used in food preservation (Magetsari et al., 2014). Cinnalmaldehyde was proved to have anti-proteolytic activity against $P$ s. aeruginosa, which support the full recovery of the infected tissue (El-Malek et al., 2016). In this study cinnamon was the most active anti-proteolytic agent and it was encapsulated in two drug carriers (chitosan and liposome nanoparticles) one at a time. As suggested by Cui et al. (2016) liposomes with smaller particle sizes $(<200 \mathrm{~nm})$ can have higher entrapment efficiency. On the other hand, Zeta potential is a vital parameter characterizing the dispersibility and stability of any nano-system. The higher Zeta potential means more stable nano-system due to the repelling force between the particles (Zhong et al., 2012). Zeta potentials $<-30 \mathrm{mV}$ and $>+30 \mathrm{mV}$ were both considered high (Lu et al., 2014). So in the present study, liposomes/cinnamon was found to be more stable, well aggregated as well as having higher wound healing efficiency in diabetic rat model than chitosan/cinnamon nanoparticles.

\section{REFERENCES}

Abdul Qadir, M., Shahzadi, S.K., Bashir, A., Munir, A., and Shahzad, S. 2017. Evaluation of phenolic compounds and antioxidant and antimicrobial activities of some common herbs. International Journal of Analytical Chemistry. 2017: Article ID 3475738. https://doi.org/10.1155/2017/3475738

Al Wahbi, A. 2018. Autoamputation of diabetic toe with dry gangrene: a myth or a fact? Diabetes, Metabolic Syndrome and Obesity: Targets and Therapy, 11: 255-264. https://doi.org/10.2147/DMSO.S164199

Asada, M., Nakagami, G., Minematsu, T., Nagase, T., Akase, T., Huang, L., Yoshimura, K., and Sanada, H. 2012. Novel models for bacterial colonization and infection of full-thickness wounds in rats. Wound Repair and Regeneration. 20(4): 601-610. https://doi.org/10.1111/j.1524-475x. 2012.00800.x

Bangham, A.D., Hill, M.W., and Miller, N.G.A. 1974. Preparation and use of liposomes as models of biological membranes. In: Methods in membrane biology. Boston (MA): Springer. p.1-68.

Cui, H.Y., Zhou, H., and Lin, L. 2016. The specific antibacterial effect of the salvia oil nanoliposomes against Staphylococcus aureus biofilms on milk container. Food Control. 61: 92-98. https://doi.org/10.1016/j.foodcont. 2015.09.034 
Cushnie, T.P., and Lamb, A.J. 2005. Review Antimicrobial activity of flavonoids. International Journal of Antimicro. Agents. 26: 343-356. https://doi.org/ 10.1016/j.ijantimicag.2005.09.002

Dunyach-Remy, C., Ngba Essebe, C., Sotto, A., and Lavigne, J.P. 2016. Staphylococcus aureus toxins and diabetic foot ulcers: role in pathogenesis and interest in diagnosis. Toxins. 8(7): 209 https://doi.org/10.3390/ toxins 8070209

El-Malek, F.F.A., Youssef, A.S., and Samy, A. 2016. Novel medical properties of Cinnamomum zeylanicum oil against Pseudomonas aeruginosa. Journal of Pure and Applied Microbiology. 10(1): 121-128.

Elnaggar, Y.S., Talaat, S.M., Bahey-El-Din, M., and Abdallah, O.Y. 2016. Novel lecithin-integrated liquid crystalline nanogels for enhanced cutaneous targeting of terconazole: development, in vitro and in vivo studies. International Journal of Nanomedecine. 11: 5531-5547 https://doi.org/10. 2147/IJN.S117817.

El-Refaie, W.M., Elnaggar, Y.S., El-Massik, M.A., and Abdallah, O.Y. 2015. Novel curcumin-loaded gel-core hyaluosomes with promising burn-wound healing potential: development, in-vitro appraisal and in-vivo studies. International Journal of Pharmaceutics. 486(1-2): 88-98 https://doi.org/ 10.1016/j.ijpharm.2015.03.052

Jashni, M.K., Mehrabi, R., Collemare, J., Mesarich, C.H., and De Wit, P.J. 2015. The battle in the apoplast: further insights into the roles of proteases and their inhibitors in plant-pathogen interactions. Frontiers in Plant Science. 6: 584. https://doi.org/10.3389/fpls.2015.00584

John, A.T., and Sharkey, M. 2018. Diabetic foot infections. Emergency Management of Infectious Diseases. p.228-232. https://doi.org/10.1017/ 9781316597095.035

Kasim, N.N., Ismail, S.N., Masdar, N.D., Hamid, F.A., and Nawawi, W.I. 2014. Extraction and potential of cinnamon essential oil towards repellency and insecticidal activity. International Journal of Scientific and Research Publications. 4(7): 2250-3153.

Lepäntalo, M., Apelqvist, J., Setacci, C., Ricco, J.B., De Donato, G., Becker, F., Robert-Ebadi, H., Cao, P., Eckstein, H.H., De Rango, P., et al. 2011. Chapter V: diabetic foot. European Journal of Vascular and Endovascular Surgery. 42: S60-S74. https://doi.org/10.1016/S1078-5884(11)60012-9

Lu, Q., Lu, P.M., Piao, J.H., Xu, X.L., Chen, J., and Zhu, L. 2014. Preparation and physicochemical characteristics of an allicin nanoliposome and its release behavior. Lwt-Food Science Technology. 57: 686-695. https://doi. org/10.1016/j.lwt.2014.01.044 
Magetsari, R., Dewo, P., Saputro, B.K., and Lanodiyu, Z. 2014. Cinnamon oil and chitosan coating on orthopaedic implant surface for prevention of staphylococcus epidermidis biofilm formation. Malaysian Orthopaedic Journal. 8(3): 11-14. https://doi.org/10.5704/MOJ.1411.003

Matougui, N., Boge, L., Groo, A.C., Umerska, A., Ringstad, L., Bysell, H., and Saulnier, P. 2016. Lipid-based nanoformulations for peptide delivery. International Journal of Pharmaceutics. 502(1-2): 80-97 https:// doi.org/10.1016/j.ijpharm.2016.02.019

Matshetshe, K.I., Parani, S., Manki, S.M., and Oluwafemi, O.S. 2018. Preparation, characterization and in vitro release study of $\beta$ cyclodextrin/chitosan nanoparticles loaded Cinnamomum zeylanicum essential oil. International Journal of Biological Macromolecules. 118: 676682. https://doi.org/10.1016/j.ijbiomac.2018.06.125

Menestrina, G., Schiavo, G., and Montecucco, C. 1994. Molecular mechanisms of action of bacterial protein toxins. Molecular Aspects of Medicine. 15(2): 79-193. https://doi.org/10.1016/0098-2997(94)90043-4

Mishra, S. 2016. Nanotechnology in medicine. Indian Heart Journal. 68(3): 437.

Nelson, E.A., Wright-Hughes, A., Brown, S., Lipsky, B.A., Backhouse, M., Bhogal, M.S., Ndosi, M., Reynolds, C., Sykes, G., Dowson, C., et al. 2016. Concordance in diabetic foot ulceration: a cross-sectional study of agreement between wound swabbing and tissue sampling in infected ulcers. Health Technology Assessment. 20(82): 1-176. https://doi.org/10. 3310/hta20820

Okpe, A.C., Nwadike, K., Uwaezuoke, N.J., Eze, O.U., Anieze, C.E., Nwoke, O.C., Ali, G.U., Shu, E.N., and Udeinya, I.J. 2019. Effects of fractionated neem leaf extract (irc) on blood glucose level in alloxan induced diabetic wistar rats. International Journal of Diabetes and Clinical Research. 6(2): 105. https://doi.org/10.23937/2377-3634/1410105

Ortiz, G.E., Noseda, D.G., Ponce Mora, M.C., Recupero, M.N., Blasco, M., and Albertó, E. 2016. A comparative study of new Aspergillus strains for proteolytic enzymes production by solid state fermentation. Enzyme Research. 2016: Article ID 3016149. https://doi.org/10.1155/2016/3016149

Philibert, T., Lee, B.H., and Fabien, N. 2017. Current status and new perspectives on chitin and chitosan as functional biopolymers. Applied Biochemistry and Biotechnology. 181(4): 1314-1337. https://doi.org/10.1007/s12010-0162286-2

Rampino, A., Borgogna, M., Blasi, P., Bellich, B., and Cesàro, A. 2013. Chitosan nanoparticles: preparation, size evolution and stability. International Journal of Pharmaceutics. 455(1-2): 219-228. https://doi.org/10.1016/j.ijpharm. 2013.07.034 
Rathor, S., Bhatt, D.C., Aamir, S., Singh, S.K., and Kumar, V. 2017. A comprehensive review on role of nanoparticles in therapeutic delivery of medicine. Pharmaceutical Nanotechnology. 5(4): 263-275. https://doi. org/10.2174/2211738505666171113130639

Shapiro, R., and Vallee, B.L. 1991. Interaction of human placental ribonuclease with placental ribonuclease inhibitor. Biochemistry. 30(8): 2246-2255. https://doi.org/10.1021/bi00222a030

Srikanth, S., and Chen, Z. 2016. Plant protease inhibitors in therapeutics-focus on cancer therapy. Frontiers in Pharmacology. 7: 470. https://doi.org/ 10.3389/fphar.2016.00470

Tuzcu, Z., Orhan, C., Sahin, N., Juturu, V., and Sahin, K. 2017. Cinnamon polyphenol extract inhibits hyperlipidemia and inflammation by modulation of transcription factors in high-fat diet-fed rats. Oxidative Medicine and Cellular Longevity. 2017: Article ID 1583098. https://doi.org/10.1155/ 2017/1583098

Zhong, Y., Wang, J., Wang, Y., and Wu, B. 2012. Preparation and evaluation of liposome- encapsulated codrug LMX. International Journal of Pharmaceutics. 438: 240-248. https://doi.org/10.1016/j.ijpharm.2012.08. 051 